\title{
BLOGS DE PETROLINA/PE E JUAZEIRO/BA E O TRATAMENTO DE PAUTAS RACIAIS
}

\author{
Rute Almeida de Lima \\ Victória Santana Oliveira \\ Vitória Luísa V. A. da Silva \\ Céres Santos \\ Márcia Guena ${ }^{1}$
}

\begin{abstract}
RESUMO
Este artigo apresenta parte dos resultados da pesquisa "A cobertura da questão racial nos blogs do Vale do São Francisco", onde além de discutir definições sobre blogs, apresenta dados quantitativos sobre matérias publicadas no período de $1^{\circ}$ de julho de 2019 a 31 de dezembro de 2019, sobre temas ligados a questão racial no Brasil nos blogs localizados nas cidades de Juazeiro/BA e Petrolina/PE. Nesse caso, foram objeto de estudo oito blogs de Petrolina e 10 de Juazeiro/BA. No total foram localizadas 122 matérias nos blogs de Petrolina e 113 em Juazeiro. $\mathrm{O}$ tema da pesquisa decorre do crescimento vertiginoso de blogs na região e da necessidade de termos dados sobre mídia e a questão racial recorrendo a agenda setting e a proposta de espiral do silêncio. Metodologicamente, esse artigo recorre ao Mapeamento Sistemático (MS), pesquisa quanti qualitativa e Análise de Conteúdo.
\end{abstract}

Palavras-chave: Racismo. Jornalismo. Blogs. Petrolina. Juazeiro.

\section{BLOGS FROM PETROLINA/PE AND JUAZEIRO/BA AND THE RACIAL STAVE TREATMENT}

\begin{abstract}
This article shows a piece of the results from the research: "The approach of racial issues by blogs from the São Francisco Valley", where, besides discussing the definitions of blogs, it shows the quantitative data about the published news from July 1st 2019 to December 31th 2019, about topics related to racial issues in Brazil on the blogs placed in Juazeiro/BA and Petrolina/PE. On this specific situation, the objects of study were eight blogs from Petrolina/PE and ten from Juazeiro/BA. The amount of news that were found was 122 on the blogs from Petrolina and 113 on the blogs from Juazeiro. The research topic comes from a huge increasement on the amount of blogs that have been created and the need of having data about the media and the racial issues. Metodologicly speaking, this article runs through systematic mapping (SM), "quanty quantitative" research, Subject analysis and "silence spiral".
\end{abstract}

Keywords: Racism. Journalism. Blogs. Petrolina. Juazeiro.

\section{BLOGS DE PETROLINA/PE Y JUAZEIRO/BA Y EL TEMA DE LAS CUESTIONES RACIALES}

\footnotetext{
${ }^{1}$ Coordenadora do Grupo RHECADOS
} 


\section{RESUMEN}

Este artículo presenta parte de los resultados de la investigación "La cobertura de la cuestión racial en blogs del Vale do São Francisco", donde además de discutir definiciones acerca de "blogs", presenta datos cuantitativos sobre artículos publicados en el período del 1 de julio. 2019 al 31 de diciembre de 2019, enfocados en temas relacionados con la cuestión racial en Brasil, en blogs ubicados en las ciudades de Juazeiro/BA y Petrolina/PE. En este caso se estudiaron ocho blogs de Petrolina/PE y 10 de Juazeiro/BA. En total, se encontraron 122 artículos en los blogs de Petrolina y 113 en Juazeiro. El tema de la investigación surge del vertiginoso crecimiento de los blogs en la región y la necesidad de datos sobre los medios y el tema racial. Metodológicamente, este artículo utiliza mapeo sistemático (MS), investigación cuanti-cualitativa, análisis de contenido y espiral de silencio.

Palabras clave: Racismo. Periodismo. Blogs. Petrolina. Juazeiro.

\section{Introdução}

As mudanças provocadas pelas Tecnologias da Informação e da Comunicação (TIC's) têm gerado novas possibilidades e práticas tanto de produção de notícias, como na criação de novos mecanismos de divulgação imediata de notícias. Nesse sentido, os blogs têm dado uma nova dinâmica ao Jornalismo digital. Criado em dezembro de 1997 pelo norte-americano John Barger, os blogs se tornaram um fenômeno virtual que oferece aos/às internautas um espaço de expressão e comunicação através de imagens, links e informações. Essa ferramenta alcançou grande popularidade no ciberespaço sendo capaz de reconfigurar não apenas a realidade virtual como a indústria cultural, política e muitas outras áreas da produção do conhecimento e das relações sociais.

Voltados para os mais diversos fins, essa ferramenta oferece grandes possibilidades para que a cultura de massa possa produzir e circular informações com recursos mínimos e acessíveis. Estatísticas que variam em fontes como Ibope/NetRatings, Intel e outras apontam que há mais de 10 anos existiam cerca de seis milhões de blogs e nove milhões de usuários ativos no Brasil (LEMOS, 2009, p.11).

Importa compreender que tal como as demais mídias, os blogs também possuem linhas editoriais distintas, fundamentadas pelas identidades e compromissos com tendências ou grupos políticos. E identificar esses lugares de fala é fundamental para que se entenda as narrativas discursivas de cada um desses veículos.

A escolha do tema dessa pesquisa não foi aleatória. Deu-se em decorrência do crescimento vertiginoso de blogs nas cidades vizinhas de Juazeiro (BA) e Petrolina (PE), a exemplo do que já ocorre em todo o país. Na verdade, essa pesquisa fornece 
uma visão do cenário dos blogs nas duas cidades, onde os blogs são um instrumento abrangente, muitas vezes, priorizados por veículos jornalísticos e que carregam um potencial singular de veiculação de ideias políticas que podem transformar a vida da população local.

Sendo assim, este artigo apresenta parte dos resultados da pesquisa "A cobertura da questão racial nos blogs do Vale do São Francisco", coordenada pelas professoras Dras. Céres Santos e Márcia Guena dos Santos. O estudo analisa dados quantiqualitativos de questões relacionadas ao racismo no Brasil nos blogs examinados, no período de $1^{\mathrm{o}}$ de julho de 2019 a 31 de dezembro de 2019, com a finalidade de identificar essas narrativas, bem como apresentar dados sobre a cobertura desse tema. No total foram analisados $18 \mathrm{blogs}$, oito de Petrolina/PE e 10 de Juazeiro/BA.

$\mathrm{O}$ artigo foi estruturado em duas partes: na primeira, apresentamos os marcos teóricos e metodológicos da pesquisa. É onde fazemos uma breve reflexão sobre a utilização dos blogs como estratégias do jornalismo na sociedade atual, fazemos reflexões sobre agenda setting e Espiral do Silêncio e tratamos sobre pesquisa quantiqualitativa e Análise de Conteúdo. Na segunda etapa, apresentamos parte dos dados apurados, as análises desses materiais e as nossas Considerações Finais.

\section{A utilização dos blogs como estratégia jornalística na sociedade contemporânea}

No artigo "Da redação aos blogs: a busca por novos arranjos econômicos e alternativos ao trabalho jornalístico", Nonato (2018) nos ajuda a entender os blogs como novas alternativas do trabalho jornalístico na atualidade e a identificar as ferramentas adequadas. Mas antes, precisamos entender que uma das primeiras popularizações dos blogs foi a sua utilização como diários pessoais, que por sua vez, era documentado por vários autores. Segundo Amaral et. al (2009), na atualidade, o uso de blogs com esta finalidade ainda é apontado por muitos autores como o seu uso mais popular.

Por sua vez Trasel (2009) ao elaborar estudos sobre a ubiquidade, isto é, a capacidade de estar concomitantemente em todos os lugares, dos blogs na web, compreendeu esta plataforma como um veículo de informação e comunicação que atinge a todos os grupos e classes sociais. "Conforme o serviço de buscas Technorati, em abril de 2007, o número de blogs monitorados ultrapassava os 70 milhões, sendo 
que, em média, 120 mil novos blogs eram criados por dia”, (SIRF apud TRASEL, 2009, p.93). A priori, em seu trabalho, Trasel (2009) elaborou conceitos e definiçõoes da ferramenta:

A definição primordial de weblog é a de um sítio dedicado a coletar links para outros sítios da rede mundial de computadores e comentálos. A partícula 'log' remete aos diários de navegação (...) O prefixo 'web' indica a transposição desses verdadeiros guias de navegação para a rede mundial de computadores de interface gráfica (TRASEL, 2009, p.94-95).

Deste modo, entende-se que um dos objetivos principais dos pioneiros na blogosfera era também obter uma ferramenta capaz de guardar arquivos de referências interessantes numa época em que esta plataforma ainda era considerada como 'primitiva'. Contudo, o avanço do ciberespaço e seu crescimento acelerado proporcionaram ferramentas que potencializaram a amplitude dessa ferramenta.

A globalização também atinge a Comunicação a partir da proliferação de canais de comunicação e de difusão da informação, e da emergência dos monopólios, que começam a se formar no final do século XIX e se transformaram em grandes empresas, corporações e conglomerados multinacionais. (THOMPSON apud NONATO, 2018, p.4).

No prefácio do livro "Blogs.com: estudos sobre blogs e comunicação", Lemos (2009, 17-18) traz a seguinte consideração a respeito da pluralidade do ciberespaço nos dias de hoje: "a reconfiguração da cibercultura criou um ambiente mais rico, já que hoje, como usuários, temos mais opções de escolha de informação e, pela primeira vez, podemos publicar e distribuir, de forma planetária, conteúdo em forma de áudio, texto, foto, vídeo".

Enquanto artefatos culturais, os $b \log s$, possuem linhas editoriais que são construídas ideologicamente através de ideias diferentes, uma vez ocupados por internautas e comunicadores/as que compreendem grupos culturais diversos no ciberespaço. Amaral el. al (2009) destacam ainda que esse instrumento comunicacional pode ser considerado um grande símbolo de aceitação social e representar canais confiáveis de comunicação.

As novas mídias trouxeram maior agilidade e eficiência para comunicadores e internautas. A noção de política e outros assuntos foram alargados em tempo real, 
superando o rádio e a televisão. “A globalização afetou não só os modos de produção dos produtos comunicacionais, como também os profissionais e as rotinas da área da comunicação", (NONATO, 2018, p.4).

O jornalismo digital e, junto a ele, os blogs e as redes sociais, atuam com inovações no fazer jornalístico que foram incorporadas e adotadas como alternativas pelos profissionais da área, visto que a tecnologia resultou na modificação de todas as nossas relações, entre elas as profissionais. É fundamental que jornalistas e comunicadores entendam a crise do sistema midiático tradicional e a precarização do trabalho jornalístico para compreender onde estão sendo inseridos nesse novo contexto e estejam preparados para atender as demandas do mercado e da sociedade atual.

as inovações trazidas pelo blog está o fato de que o jornalista não precisa da estrutura de uma empresa para se comunicar, tem a possibilidade de escrever em qualquer local e, principalmente com isenção, sem a interferência de interesses comerciais e/ou das empresas de comunicação, ideias que, a princípio, remetem à realização de um sonho. Nessa condição, o jornalista se vê como um empreendedor social. (NONATO, 2018, p.7)

Nesse sentido, os blogs aparecem como uma ferramenta que permite o desenvolvimento dessas habilidades para os jornalistas na atualidade. Ainda, surgem como uma alternativa rentável que não exige condições operacionais de alto custo e possibilitam uma postagem e atualização de conteúdos de forma rápida e acessível.

Também utilizamos neste artigo os pressupostos da Agenda Setting, segundo Wolf (2006). Ele defende que as pessoas têm a tendência de conhecer e discutir aquilo que é vinculado com maior destaque nos mass media, isto é, o conjunto de meios de comunicação em massa: "em consequência da ação dos jornais, da televisão e dos outros meios de informação, o público sabe ou ignora, presta atenção ou descura, realça ou negligencia elementos específicos dos cenários públicos”. (SHAW, 1979, p. 96, apud WOLF, 2006, p.62).

A partir disso, pressupõe-se que muito da compreensão da realidade social que as pessoas têm é baseada no conteúdo disseminado pelos mass media. Dessa forma, essa compreensão da realidade acaba sendo reflexo de uma representação que não é capaz de traduzir integralmente a verdade. 
Na medida em que o destinatário não é capaz de controlar a precisão da representação da realidade social, tendo por base um standard exterior aos mass media, a imagem que, por intermédio dessa representação, ele forma, acaba por ser distorcida, estereotipada ou manipulada. A hipótese coloca, portanto, o problema de uma continuidade a nível cognitivo, entre as distorções que se geram nas fases produtivas da informação e os critérios de relevância, de organização dos conhecimentos, que os consumidores dessa informação absorvem e de que se apropriam (ROBERTS, 1972, p. 380 apud WOLF, 2006, p. 63).

Sendo assim, Wolf (2006) afirma que os mass media criam representações de "pacotes" da realidade em que os indivíduos "vivem", exclusivamente, em função de ou através da mediação simbólica dos meios de comunicação de massa. Dessa maneira, a hipótese do agenda setting toma como postulado um impacto direto dos mass media sobre os destinatários, que acontecem segundo dois níveis: primeiro, a "ordem do dia", que define os temas, assuntos e problemas vinculados aos mídias de massa, e, depois, a "hierarquia de importância e de prioridade" que organiza os elementos dispostos na "ordem do dia".

Além disso, sobre essa forma de organização das informações, Wolf (2006, p.65) afirma que o "modo de hierarquizar os acontecimentos ou os temas públicos importantes, por parte de um sujeito, assemelha-se à avaliação desses mesmos problemas feita pelos mass media". Ademais, é importante lembrar que a ação do agendamento é mais significativa no que diz respeito às escolhas dos assuntos discutidos do que em como esses assuntos estão sendo discutidos. Outro mecanismo de agenda-setting é a omissão, a não cobertura de certos temas, a cobertura intencionalmente modesta ou marginalizada que alguns assuntos recebem.

Este tipo de agenda-setting funciona, certamente, para todos os mass media, para lá das diferenças técnicas, jornalísticas, de linguagem, pelo simples fato de o acesso a fontes alternativas àquelas que garantem o fornecimento constante de notícias, ser bastante difícil e oneroso. Entre os diferentes mass media podem existir modos diversos de provocar o efeito de agenda-setting por omissão, mas todos, em certa medida, incorrem nele e com certeza também o sistema informativo no seu conjunto (WOLF, 2006, p. 65).

Logo, a hipótese do agenda setting defende que os mass media são eficazes na construção da imagem da realidade que o sujeito vem estruturando. Essa imagem pode ser pensada como um modelo em relação ao qual a nova informação é confrontada para 
lhe conferir o seu significado e inclui o quadro de referência e as necessidades, crenças e expectativas que influenciam a formação da opinião pública. A reflexão sobre a Espiral do Silêncio, desenvolvida nos anos 60 pela estudiosa alemã Noelle Neumann, (apud MENDONÇA e BRAGA, 2015), para quem a mídia desempenha um importante papel no processo de convencimento das minorias. Isto é, os mídias priorizam o discurso da maioria ou que se apresenta desta forma, em detrimento de discursos considerados impopulares, fato que potencializa o silenciamento de alguns grupos.

Sendo assim, quando um indivíduo está inserido em um meio onde suas opiniões diferem do conceito estabelecido pela maioria, existe a tendência de que ele omita o que pensa para continuar integrado a um grupo e fugir do isolamento. Nesse sentido, devemos considerar que, por vezes, a narrativa pode nem mesmo corresponder a opinião da maioria. Entretanto, sua exposição massiva, potencializa sua influência na dita 'opinião popular'.

\section{Métodos de Pesquisa}

Além de pesquisa documental indireta, esse trabalho recorre à pesquisa quantiqualitativa, ao Mapeamento Sistemático (MS) e Análise de Conteúdo. Através da Pesquisa quanti-qualitativa buscamos compreender os dados apresentados por meio de tabelas e gráficos, dessa forma, foi possível examinar e explicar possíveis razões ou motivações que esclareçam o cenário apresentado pelos dados. Deste modo, a interpretação e o entendimento das informações coletadas na pesquisa tornam-se cruciais, pois ajuda no processo de compreensão dos fenômenos através da coleta de dados narrativos, estudando particularidades e experiências individuais.

Bardin (2004, p. 27) considera a Análise de Conteúdo como "um conjunto de técnicas de análise das comunicações”, que permite uma diversidade de análises. Pode contribuir na análise de 'significados' (temática), mesmo que tenha semelhanças com análise dos 'significantes', que faz análises lexical e de procedimentos. Bardin (2004) entende que Análise de Conteúdo contribui para a descrição objetiva e precisa do que é dito sobre um determinado tema, lugar e espaço. 
Para utilizarmos a Análise de Conteúdo, foi necessário recorrer ao processo de Mapeamento Sistemático (MS) para a localização das matérias alvo da pesquisa. Segundo Falbo (2018):

Um Mapeamento Sistemático (MS) é uma revisão ampla dos estudos primários existentes em um tópico de pesquisa específico que visa identificar a evidência disponível nesse tópico. Assim, um MS é um estudo secundário que tem como objetivo identificar e classificar a pesquisa relacionada a um tópico amplo de pesquisa (KITCHENHAM; CHARTERS, 2007, apud FALBO, 2018, p.1).

O MS envolveu três fases após a definição do tema e objetivos da pesquisa. A primeira delas se deu pela busca e coleta de matérias nos sites escolhidos para a pesquisa: realizou-se a consulta às fontes de pesquisa. Essa fase compreendeu também a definição do string de busca. A segunda fase de aplicação do mapeamento sistemático foi a filtragem do corpus: uma vez indicados, os textos a serem analisados foram selecionados por meio da aplicação de critérios de seleção de inclusão e de exclusão.

A terceira etapa consistiu na apresentação dos resultados colhidos desde o início da pesquisa, registrados e sintetizados em tabelas. Sobre este estágio, são esclarecedoras as palavras de Falbo (2018):

Resultados de um MS ajudam a identificar lacunas nesta área, capazes de sugerir pesquisas futuras e prover um guia para posicionar adequadamente novas atividades de pesquisa (KITCHENHAM; CHARTERS, 2007; KITCHENHAM et al., 2011; PETERSEN et al., 2008). Assim, MSs visam prover uma visão geral de um tópico e identificar se há subtópicos nos quais mais estudos primários são necessários. (FALBO, 2018, p.1).

\section{Apresentação de dados quantitativos da pesquisa}

A pesquisa foi desenvolvida de $1^{\circ}$ de julho de 2019 a 31 de dezembro de 2019 em 18 blogs, sendo 10 de Juazeiro/BA e oito de Petrolina/PE conforme tabela abaixo:

\begin{tabular}{|l|l|}
\hline \multicolumn{1}{|c}{ LISTA DE BLOGS JUAZEIRO-BA } & \multicolumn{1}{c}{ LISTA DE BLOGS PETROLINA-PE } \\
\hline Rede GN (Geraldo José) & Ponto Crítico de Ângela Santana \\
\hline Preto no Branco & Carlos Brito \\
\hline 60 graus & Waldney Passos \\
\hline
\end{tabular}




\begin{tabular}{|l|l|}
\hline Portal Zap & Blog Josélia Maria \\
\hline Vale Comentar & Edenevaldo Alves \\
\hline Ação Popular & Blog do Banana \\
\hline Vale em Foco & Blog do Daniel Campos \\
\hline A Notícia do Vale & Blog do Patrício Nunes \\
\hline Ramos Filho & TOTAL DE BLOGS: 8 \\
\hline Blog Opará & \\
\hline TOTAL DE BLOGS: 10 & \\
\hline
\end{tabular}

\section{Apresentação de dados quantitativos da pesquisa nos blogs de Juazeiro (BA)}

No período de $1^{\circ}$ de julho de 2019 a 31 de dezembro de 2019, identificamos 113 matérias nos 10 blogs de Juazeiro/BA. Constata-se que os blogs Preto no Branco e Ação Popular são os que mais publicaram matérias ligadas a essa pesquisa. Nota-se que os meses de maior publicação foram novembro (42), dezembro (32), outubro (14) e julho (14). As matérias foram distribuídas, mensalmente da seguinte maneira:

\begin{tabular}{|c|c|c|c|c|c|c|c|}
\hline \multicolumn{8}{|c|}{$\begin{array}{l}\text { BLOGS JUAZEIRO- TOTAL DE MATÉRIAS CONTENDO PALAVRAS-CHAVES PROPOSTAS } \\
\text { (Julho-Dezembro 2019) }\end{array}$} \\
\hline $\begin{array}{l}\text { NOMES DOS } \\
\text { BLOGS }\end{array}$ & JULHO & AGOSTO & $\begin{array}{l}\text { SETEMBR } \\
\text { O }\end{array}$ & $\begin{array}{l}\text { OUTUBR } \\
\text { O }\end{array}$ & $\begin{array}{l}\text { NOVEM } \\
\text { BRO }\end{array}$ & $\begin{array}{l}\text { DEZEMB } \\
\text { RO }\end{array}$ & TOTAL \\
\hline $\begin{array}{l}\text { Rede GN (Geraldo } \\
\text { José) }\end{array}$ & 2 & 0 & 1 & 3 & 9 & 0 & 15 \\
\hline Preto no Branco & 6 & 1 & 2 & 6 & 17 & 10 & 42 \\
\hline 60 graus & 0 & 0 & 0 & 0 & 1 & 1 & 2 \\
\hline Portal Zap & 0 & 0 & 0 & 0 & 0 & 1 & 1 \\
\hline Vale Comentar & 0 & 0 & 0 & 2 & 2 & 3 & 7 \\
\hline Ação Popular & 4 & 3 & 2 & 3 & 11 & 17 & 40 \\
\hline Vale em Foco & 1 & 1 & 0 & 0 & 1 & 0 & 3 \\
\hline A Notícia do Vale & 0 & 0 & 0 & 0 & 0 & 0 & 0 \\
\hline Ramos Filho & 0 & 0 & 1 & 0 & 0 & 0 & 1 \\
\hline Blog Opará & 1 & 0 & 0 & 0 & 1 & 0 & 2 \\
\hline TOTAL & 14 & 5 & 6 & 14 & 42 & 32 & $\begin{array}{l}\text { TOTAL DE } \\
\text { MATÉRIAS: } \\
113\end{array}$ \\
\hline
\end{tabular}




\section{TOTAL DE}

BLOGS: 10

\section{Quantidade de matérias por blog}

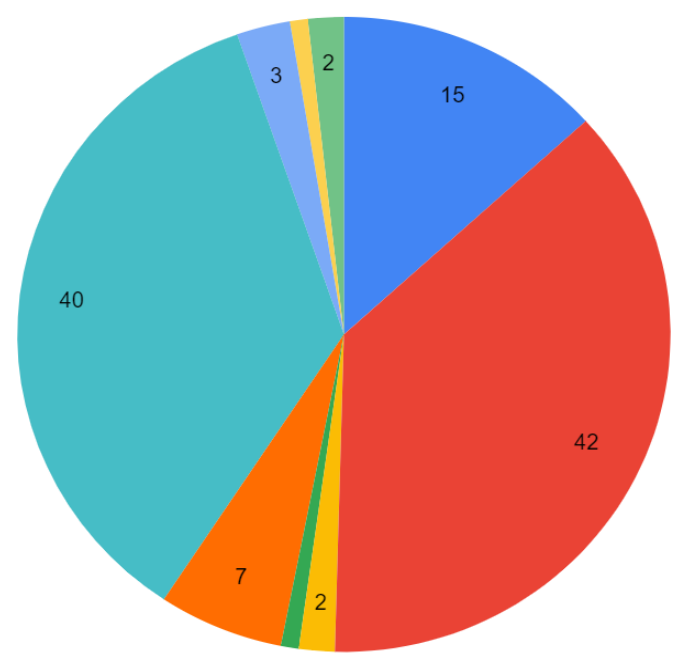

Rede GN (Geraldo José)

Preto no Branco

60 graus

Portal Zap

Vale Comentar

- Ação Popular

Vale em Foco

C Ramos Filho

Blog Opará

Quantidade de matérias por mês
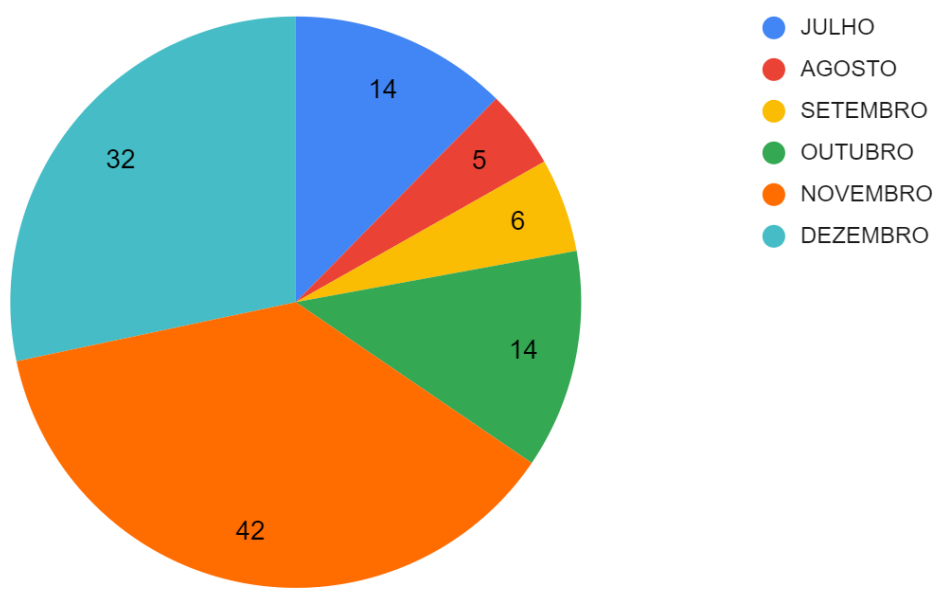

Foram utilizadas 22 palavras-chave para localizar matérias que contemplassem o contexto racial: "intolerância religiosa", "racismo", "negro", "Candomblé”, "cultura negra”, "racismo religioso", “macumba", “orixás", "aguadê”, “terreiros”, “Umbanda", "mãe de santo", "pai de santo", "babalorixá", "yalorixá", "lei 10.639”, "preconceito 
religioso", "preconceito", “20 de novembro", "consciência negra”, "13 de maio", "Exu".

Vale destacar, que esses dados se referem ao total de 113 matérias publicadas no período pesquisado - $1^{\circ}$ de julho de 2019 a 31 de dezembro de 2019 - e que foram localizadas por meio do mecanismo Google Advanced Search, de palavras-chave e dos domínios dos sites pesquisados. Na verdade, localizamos mais 13 matérias com algumas das palavras-chaves. Entretanto, ao ler o conteúdo notou-se que não havia nenhuma relação com questões raciais, tema desta pesquisa.

Das 22 palavras-chave verificamos que não foi localizada nenhuma matéria no

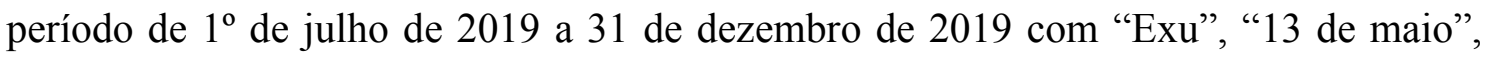
“lei 10.639”. A primeira palavra, Exu, sempre aparece, apenas relacionada à cidade pernambucana e/ou ao cantor e compositor Luiz Gonzaga. As palavras que possuem relação com religiões de matriz africana, como "pai de santo", "mãe de santo", "orixás", "aguadê", "terreiros", "Candomblé", "babalorixá", "yalorixá” também não aparecem nos títulos ou em conteúdo publicado, com exceção de "Umbanda" que foi possível localizar duas sobre o tema e "macumba" que aparece em uma publicação, mas de forma pejorativa e, indiretamente, em uma outra matéria como feitiçaria.

Foi possível identificar que o uso da expressão "cultura negra", está relacionada a eventos promovidos pelas prefeituras, instituições ou pelo Movimento Negro. Já "racismo religioso", não apareceu vinculado a nenhuma temática racial. Entretanto, "negra/o", "20 de novembro" e "consciência negra" aparecem com frequência. O termo "negra/o" apareceu 34 vezes em títulos de matérias, na maioria, relacionada ao dia 20 de Novembro - Dia Nacional da Consciência Negra. Verificou-se a existência de duas publicações relacionadas ao tema "cabelo crespo".

Com relação aos títulos das publicações que usaram a palavra "racismo", ela aparece 26 vezes. Já “Quilombo" e "preconceito”, uma vez em títulos de publicações. Já o termo "Palmares" foi localizado em três postagens. Com relação aos blogs analisados, torna-se possível inferir que no site A Notícia do Vale não houve a publicação de nenhuma matéria sobre questões raciais ou relacionadas às palavraschave propostas. Opará, Ramos Filho, Vale Comentar, Vale em Foco, 60 Graus e Portal Zap possuem menos de 10 publicações sobre temáticas raciais, cada. Sendo o último um 
portal voltado para entretenimento. O blog Rede GN apresenta 15 matérias que contemplam a temática racial no período de $1^{\text {o }}$ de julho de 2019 a 31 de dezembro de 2019.

O destaque quanto ao número de publicações cabe aos portais Ação Popular com 40 e Preto no Branco com 42 matérias publicadas. Os dois veículos de comunicação possuem abordagens distintas quanto às temáticas raciais. É possível identificar no conteúdo publicado no Ação Popular alguns pontos questionáveis, como algumas matérias que possuem títulos e conteúdos que reproduzem formas de preconceito e intolerância religiosa, especialmente quando o tema abordado se refere às religiões de matriz africana. Entretanto, o site também apresenta bons textos informativos relacionados a outras questões raciais, como algumas publicações de cunho cultural.

Por outro lado, o Preto no Branco apresenta, no período da pesquisa, publicações de editoria policial, divulgação de eventos e ações relacionadas à pauta racial, além de matérias que denunciam preconceito, racismo, violência e acontecimentos no campo político que implicam em alguma consequência para a população negra. Enfatizamos que boa parte do conteúdo desses sites foi publicada entre os meses de outubro de 2019 e dezembro de 2019.

Creditamos o volume de publicações, em especial no mês de novembro de 2019, ao fato de ser o mês em que se celebra o Dia Nacional da Consciência Negra, quando há um aumento no número de eventos em prol da conscientização. Além disso, nesse mês e ano, participantes de um evento organizado pelo Movimento Negro em Petrolina/PE foram agredidos e presos por policiais do $2^{\circ}$ Batalhão Integrado Especializado $\left(2^{\circ}\right.$ Biesp). Fato que teve grande repercussão na imprensa.

\section{Apresentação dos dados quantitativos na pesquisa nos blogs de Petrolina (PE)}

Em Petrolina/PE, a pesquisa foi realizada em oito blogs e foram localizadas 122 matérias. Identificamos que os meses de maior publicação foram: novembro (67), outubro (13), julho (14) e agosto (11). O blog Ponto Crítico se destacou com o maior número de notícias ligadas à temática racial dentro do período estudado, totalizando 36 matérias.

Nele, as matérias contemplam vários ângulos da notícia e seu conteúdo se destaca pela divulgação de eventos e ações relacionadas à pauta racial, evidenciando a 
cultura negra e a publicação de matérias de denúncia contra racismo; violência e acontecimentos que implicam em alguma consequência para essa população. Logo atrás, vem o blog do Patrício Nunes com um total de 35 matérias e os blogs Josélia Maria e Edenevaldo Alves, ambos com 13 postagens.

As matérias foram distribuídas, mensalmente da seguinte maneira:

\begin{tabular}{|c|c|c|c|c|c|c|c|}
\hline \multicolumn{8}{|c|}{$\begin{array}{l}\text { BLOG PETROLINA- TOTAL DE MATÉRIAS CONTENDO PALAVRAS-CHAVES PROPOSTAS } \\
\text { (julho-dezembro 2019) }\end{array}$} \\
\hline $\begin{array}{l}\text { NOMES DOS } \\
\text { BLOGS }\end{array}$ & JULHO & AgOSTO & SETEMBRO & OUTUBRO & NOVEMBRO & DEZEMBRO & TOTAL \\
\hline $\begin{array}{l}\text { Ponto Crítico de } \\
\text { Ângela Santana }\end{array}$ & 5 & 4 & 3 & 3 & 20 & 1 & 36 \\
\hline Carlos Brito & 0 & 0 & 0 & 1 & 3 & 1 & 5 \\
\hline Waldney Passos & 0 & 1 & 1 & 2 & 3 & 1 & 8 \\
\hline Blog Josélia Maria & 0 & 1 & 2 & 1 & 8 & 1 & 13 \\
\hline Edenevaldo Alves & 3 & 0 & 0 & 0 & 9 & 1 & 13 \\
\hline Blog do Banana & 1 & 0 & 0 & 1 & 6 & 0 & 8 \\
\hline $\begin{array}{l}\text { Blog do Daniel } \\
\text { Campos }\end{array}$ & 0 & 1 & 0 & 0 & 3 & 0 & 4 \\
\hline $\begin{array}{l}\text { Blog do Patrício } \\
\text { Nunes }\end{array}$ & 5 & 4 & 4 & 5 & 15 & 2 & 35 \\
\hline TOTAL & 14 & 11 & 10 & 13 & 67 & 7 & $\begin{array}{c}\text { TOTAL DE } \\
\text { MATÉRIAS: } \\
122\end{array}$ \\
\hline $\begin{array}{l}\text { TOTAL DE } \\
\text { BLOGS: } 8\end{array}$ & & & & & & & \\
\hline
\end{tabular}




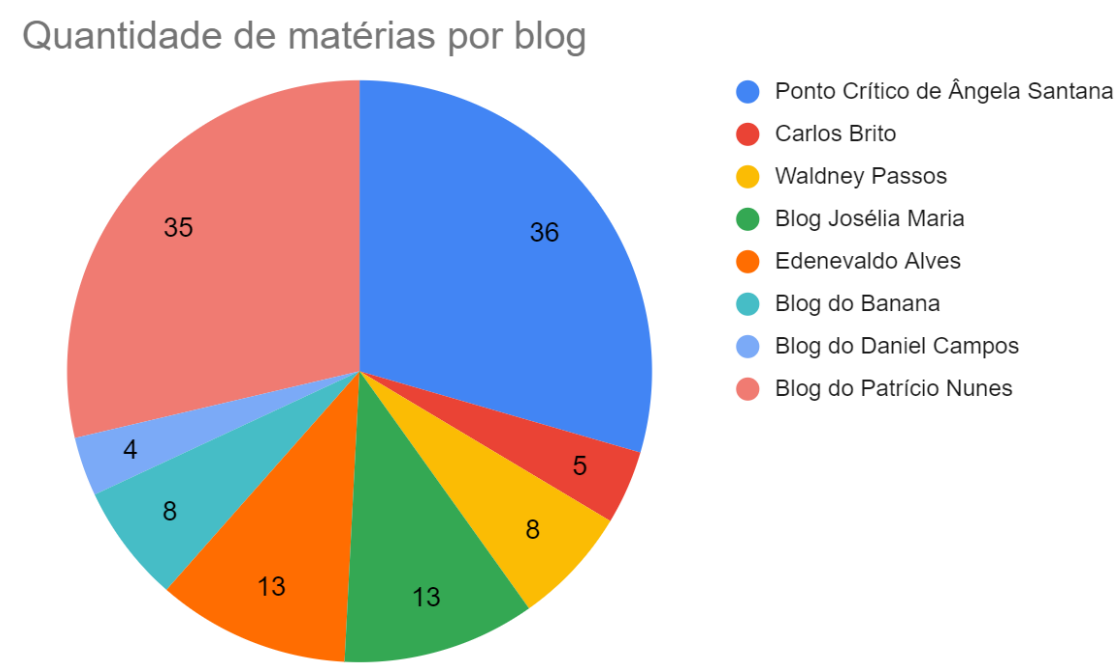

\section{Quantidade de matérias por mês}

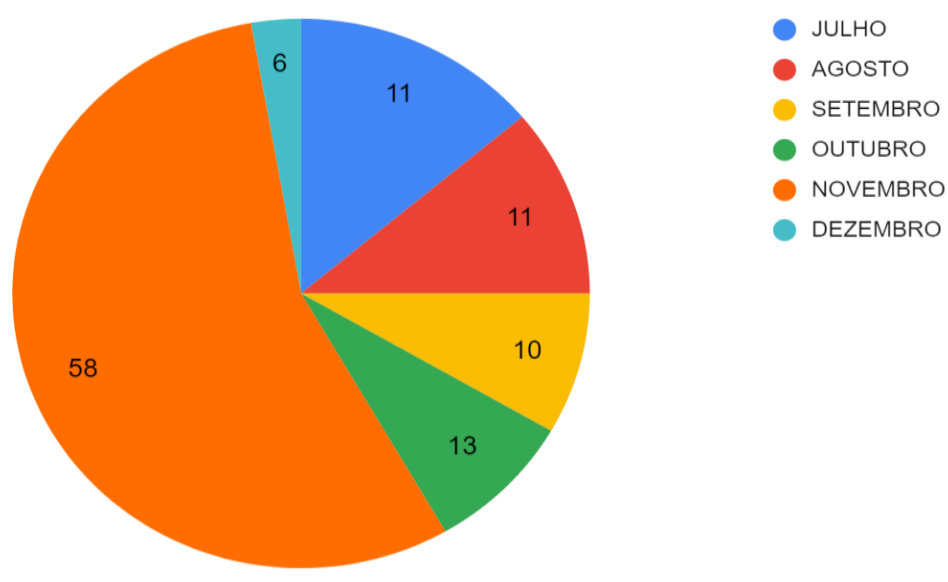

Em Petrolina-PE, foram utilizadas 36 palavras-chave para localizar as matérias de cunho racial nos blogs pesquisados dentro do período estabelecido: "intolerância religiosa", "racismo", "negro/a", "Candomblé", "cultura negra", "racismo religioso", "macumba", "orixás", "aguadê", "terreiros", "Umbanda", "mãe de santo", "pai de santo", "babalorixá", “yalorixá”, "lei 10.639”, "preconceito religioso", "preconceito", "20 de novembro", “consciência negra”, "13 de maio", "Exu”, "preto/a", “quilombola", "afro", “crioulo/a", "Palmares”, “crespo", “indígena”, "feitiçaria”, "pardos”, “escravista", "abolição", escravos", "Oxum” e "escravização".

Destacamos que as 122 matérias analisadas no período de $1^{\circ}$ de julho de 2019 a 31 de dezembro de 2019 foram localizadas através do mecanismo Google Advanced Search, de palavras-chave e dos domínios dos sites pesquisados. Das 36 palavras-chave, 
verificamos que foram localizadas apenas 24: "pretas", "racismo", "negro/a", "preconceito", “quilombola", “afro", “intolerância religiosa”, “crioula", "palmares", “crespo", “indígena”, “Umbanda", "Candomblé”, “feitiçaria”, “macumba”, “pardos”, “escravista", “abolição", “escravos”, “Oxum”, “escravização”, “exu” e as expressões "20 de novembro" e "consciência negra".

Não foi localizada nenhuma matéria com as expressões "cultura negra", "racismo religioso", "lei 10.639", "preconceito religioso" e "13 de maio". Palavras e expressões que possuem relação com religiões de matriz africana como "orixás", "aguadê", "terreiros", "babalorixá", "yalorixá", "mãe de santo" e "pai de santo" também não foram encontradas nos títulos ou em conteúdo publicado, com exceção de "Exu" que aparece apenas uma vez relacionada ao cantor e compositor Luiz Gonzaga.

Foi possível identificar que o uso das expressões "cultura negra" e "racismo religioso" também não aparecem vinculados a nenhum título ou conteúdo publicado no período de $1^{\text {o }}$ de julho de 2019 a 31 de dezembro de 2019. Entretanto, "negro(a)" e "racismo" aparecem com frequência. Outras palavras e expressões como "quilombos", "desigualdade racial”, "afrocoletividade", "genocídio negro", "genocídio da juventude negra", “antirracista", "Unegro", “preconceito racial”, “Zumbi”, "Dandara", "ancestralidade negra", "igualdade racial", "afrolab", "afrohub", "afrodescendente, "negritude" e "violência policial" foram localizadas".

O termo mais usado foi "negros/as" que apareceu 59 vezes em conteúdos majoritariamente relacionados ao dia 20 de novembro - Dia Nacional da Consciência Negra, seguido de "quilombola", "racismo" e "indígena" que apareceram nove, oito e oito vezes respectivamente. "Palmares" e "preta" aparecem seis vezes. A palavra "racial" e a expressão "violência policial" aparecem cinco vezes nos títulos das manchetes que tinham como alvo o povo preto. A expressão "igualdade racial" e a palavra "afro" aparecem três vezes cada uma. As palavras "crespo", "preconceito", "Zumbi", "Dandara" assim como as expressões "ancestralidade negra" e "genocídio da juventude negra" aparecem apenas duas vezes, cada.

Com relação aos blogs analisados, constata-se que nos blogs Daniel Campos e Carlos Britto foram os que tiveram inferior número de publicações sobre questões raciais ou relacionadas às palavras-chaves propostas. Além destes, os sites Waldiney 
Passos e Blog do Banana também possuem menos de 10 publicações sobre temáticas raciais. Os blogs Josélia Maria e Edenevaldo Alves apresentam 13 matérias, cada. Deste modo, o destaque quanto ao número de publicações cabe aos portais Ponto Crítico e Blog do Patrício Nunes com 36 e 35 publicações, respectivamente.

Os dois veículos de comunicação possuem abordagens distintas quanto às temáticas raciais. É possível identificar no conteúdo publicado no Ponto Crítico textos informativos, não tendenciosos e relacionados a essas questões, que além de informar, evidenciam aspectos culturais e valorização da cultura negra. O blog Patrício Nunes, por exemplo, apresenta, no período da pesquisa, um foco maior em publicações de editoria policial, divulgação de eventos e ações relacionadas à pauta racial. Todavia, há um destaque para denúncias de violência policial de fatos ocorridos em novembro de 2019, quando participantes de um evento organizado pelo Movimento Negro em Petrolina/PE foram agredidos e presos por policiais do $2^{\circ}$ Batalhão Integrado Especializado $\left(2^{\circ}\right.$ Biesp).

\section{Considerações Finais}

A pesquisa identificou a prática de silenciamento midiático para temas relacionados à população negra, reprodução de estruturas excludentes presentes na sociedade brasileira, situação que tem uma dimensão singular de peculiaridades. Senão vejamos: nas cidades de Petrolina/PE e Juazeiro/BA alguns blogs têm uma boa receptividade, penetração na população que usam essas mídias como fonte de notícias e informações. Por essa razão, o discurso presente nesses sites e nessas matérias tornamse narrativas importantes no processo da luta antirracista ou de reprodução de representações e estereótipos.

O blog de Juazeiro/BA, Vale em Foco, no período da pesquisa não postou, sequer, uma matéria. Nos outros blogs mapeados na cidade: 60 graus; A Notícia do Vale; Ação em Foco; Blog Opará; Geraldo José; Portal Zap; Ramos Filho; Rede GN; Preto no Branco; Vale Comentar; Vale em Foco - foi possível identificar semelhanças nas editorias apresentadas: as ações institucionais e as matérias publicadas estão diretamente relacionadas, a temática racial. Esses sites publicaram matérias cujos conteúdos foram de divulgação de eventos e promoção de campanhas que buscam fazer 
frente ao racismo. Essas iniciativas, aliás, no geral, partem das Prefeituras, Câmaras de vereadores e ativistas do Movimento Negro.

$\mathrm{Na}$ cidade baiana de Juazeiro, os termos mais utilizados nos títulos das notícias selecionadas foram: "negro/a", "quilombolas", "racismo", "pretas", "pardas", "preconceito racial”, "racial”, "Zumbi”, "Dandara", "indígenas", "afro" e "negritude”, um total de 12 palavras. A palavra "negro/a(s)" foi a que mais apareceu, agora num total de quarenta e três vezes.

Na cidade vizinha, em Petrolina, constatamos semelhanças nas linhas editoriais dos blogs pesquisados: policial, institucional e divulgação de eventos. Na maioria dos blogs analisados - Carlos Brito, Waldiney Passos, Josélia Maria, Edenevaldo Alves, Blog do Banana e Blog do Daniel Campos - percebemos a ausência de determinados temas e a negação dessas narrativas discursivas nos leva a identificar a prática de invisibilidades e impedimentos midiáticos.

Em Petrolina, as palavras "pardas", "quilombos", "exu”, "negritude" e as expressões "desigualdade racial", "20 de novembro", "genocídio negro" e "preconceito racial" foram usadas apenas uma vez. $\mathrm{Na}$ análise pode-se constatar que nas duas cidades, a palavra mais citada foi "negro/a". Interpretamos a baixa quantidade de matérias na maioria dos blogs como um silenciamento sobre o assunto, e, também, como uma negação das temáticas que foram objeto de pesquisa deste trabalho. Entendemos essa invisibilidade como a prática de um modus operandi que naturaliza essa ausência, também entendida como racismo estrutural.

Pensar a Espiral do Silêncio nos dados apurados nessa pesquisa, nos leva a refletir que em um país com aspectos históricos conhecidamente racistas, como o Brasil, os dados aqui apresentados se enquadram nesse contexto e, portanto, não são exceção ao cenário nacional. Nesse sentido a pesquisa nos possibilitou identificar três tipos de posicionamento por parte dos veículos de imprensa frente às questões raciais no período analisado pela pesquisa:

a- Blogs onde não foi possível localizar nenhuma matéria relacionada às pautas raciais;

b- Um outro grupo de sites que se caracteriza pela presença de uma produção que abarca questões raciais, mas que, em alguns caso, possuem conteúdo não solidário a luta antirracista; 
c- Um outro grupo formado por blogs que disponibilizam espaço para debater questões raciais de maneira responsável.

A carência de cobertura midiática, ou de conhecimento da sociedade brasileira, dos problemas em curso, relacionados às discussões raciais e, ainda, a falta de preocupação com o conteúdo divulgado, apareceram nessa pesquisa. Como exemplo, destacamos uma matéria publicada pelo blog Vale em Foco, em 15 de agosto de 2019 intitulada como "Mototaxista encontra macumba no centro de Juazeiro e toca fogo para quebrar maldição", meses depois em 11 de outubro de 2019, um outro site, no blog Ação Popular, também publicava uma matéria de título questionável; "Macumba braba em Juazeiro", que tratava de acontecimentos negativos que teriam ocorrido com pessoas ligadas ao governo do município e que supostamente se tratava de "macumba feita pela oposição”. Ambas servem para destacar o ainda papel dos mídias para a manutenção, retroalimentação do racismo estrutural no Brasil.

Observamos que essas matérias não são informativas porque enfatizam discursos preconceituosos, a exemplo do tratamento dado às religiões de matriz africana, que 'satanizam' essas religiões e que se fazem presentes em nossa sociedade, apesar da luta antirracista. Alguns discursos, inclusive, estimulados pelo atual Governo Federal.

Sem dúvida essa pesquisa contribui não só para um mapeamento quantitativo dos blogs nas cidades de Petrolina/PE e Juazeiro/BA, mas também, para uma identificação das posturas que adotam quando da cobertura de temas relacionados à população negra.

\section{Referências}

AMARAL, A. et al. Blogs.com: Estudos sobre blogs e comunicação. 21. ed. São PauloSP: Momento Editorial, 2009, p. 7-287.

BARDIN, Laurence; Análise do Conteúdo. 70. ed. São Paulo: Persona, 2004, p. 10222.

FALBO, Ricardo de Almeida. Mapeamento Sistemático. V. 01. Disponível em: https://inf.ufes.br/ falbo/files/MP/TP/Sobre_MS.pdf. Acesso em: 04 abr 202

MENDONÇA, Rhayssa Fernandes; BRAGA, Claudomilson Fernandes. A Espiral do Silêncio e as Representações Sociais: os meios de comunicação, a legitimação e a 
naturalização. Intercom - Sociedade Brasileira de Estudos Interdisciplinares da Comunicação. Rio de Janeiro, 4 set. 2015, p. 1-14.

LEMOS, André. Prefácio. In: AMARAL, A. et al. Blog.com: estudos sobre blogs e comunicação. 21 Ed. São Paulo-SP: Momento Editorial, 2009, p. 07-20

NONATO, Cláudia. Da Redação aos Blogs: a busca por novos arranjos econômicos e alternativas ao trabalho jornalístico. Revista Famecos, São Paulo-SP, v. 25, n. 1, p. 121, jan./2018. Disponível em:

https://revistaseletronicas.pucrs.br/ojs/index.php/revistafamecos/article/view/28086. Acesso em: 8 nov. 2020.

TRASEL, Marcelo. A vitória de Pirro dos blogs: ubiqüidade e dispersão conceitual na web. In: AMARAL, A. et al. Blog.com: estudos sobre blogs e comunicação. 21 Ed. São Paulo-SP: Momento Editorial, 2009, p. 93-108

WOLF, Mauro. Teorias da comunicação. $8^{\text {a }}$ edição. Lisboa: Presença, 2006. 